\title{
Successful clinical application of tissue-engineered graft for extracardiac Fontan operation
}

\author{
Yuji Naito, Yasuharu Imai, Toshiharu Shin'oka, Junichi Kashiwagi, Mitsuru Aoki, Manabu Watanabe, Goki Matsumura, \\ Yoshimichi Kosaka, Takeshi Konuma, Narutoshi Hibino, Akira Murata, Takeshi Miyake, and Hiromi Kurosawa, \\ Tokyo, Japan
}

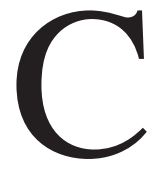

urrently satisfactory clinical results are observed with the extracardiac Fontan operation (ECFO); however, some issues associated with graft materials must be addressed, such as infection, thrombogenicity, and the lack of growth potential. ${ }^{1}$ We report here the case of a patient with occlusion of a graft implanted at initial operation and successfully underwent reoperative ECFO with a tissue-engineered graft.

\section{Clinical Summary}

A 12-year-old boy had the diagnoses of polysplenia, complete atrioventricular septal defect, small left ventricle, common atrium, bilateral superior vena cava, and hemiazygous connection. A modified Blalock-Taussig shunt and ECFO with a Hemashield graft (Boston Scientific Corporation, Meadox Division, Boston, Mass) were performed at the ages of 9 and 11 years, respectively. The patient had general fatigue 7 months after ECFO. Catheterization demonstrated occlusion of the extracardiac graft. The clinical application of tissue engineering in this patient was approved by the ethical committee at Tokyo Women's Medical University, and the patient's parents were thoroughly informed and consented to the procedure. Graft replacement with a tissue-engineered graft was planned, and graft preparation was conducted.

An approximately 2 -cm segment of peripheral vein was harvested, and cells from its walls were isolated. The cells were cultured and expanded as previously described elsewhere. ${ }^{2}$ The tubular scaffold for these cells was composed of a polycaprolactone-polylactic acid copolymer (weight ratio 1:1) reinforced with woven polyglycolic acid. The synthetic biodegradable polymer conduit (20 $\mathrm{mm}$ in diameter and $1 \mathrm{~mm}$ in thickness) was designed so that it would be degraded within 8 weeks. Ten days after seeding, the replacement of the occluded conduit was performed by transplantation of the tissue-engineered graft.

Intraoperative findings showed that the conduit was completely collapsed and flattened, with white thrombus contained within.

From the Department of Cardiovascular Surgery, Heart Institute of Japan, Tokyo Women's Medical University, Tokyo, Japan.

Received for publication Feb 22, 2002; accepted for publication July 23, 2002.

Address for reprints: Yuji Naito, MD, Department of Cardiovascular Surgery, Heart Institute of Japan, Tokyo Women's Medical University, 8-1, Kawada-cho, Shinjyuku-ku, Tokyo, 162-8666, Japan (E-mail: ujinaito@aol.com).

J Thorac Cardiovasc Surg 2003;125:419-20

Copyright (C) 2003 by The American Association for Thoracic Surgery

$0022-5223 / 2003 \$ 30.00+0$

doi: $10.1067 / \mathrm{mtc} .2003 .134$

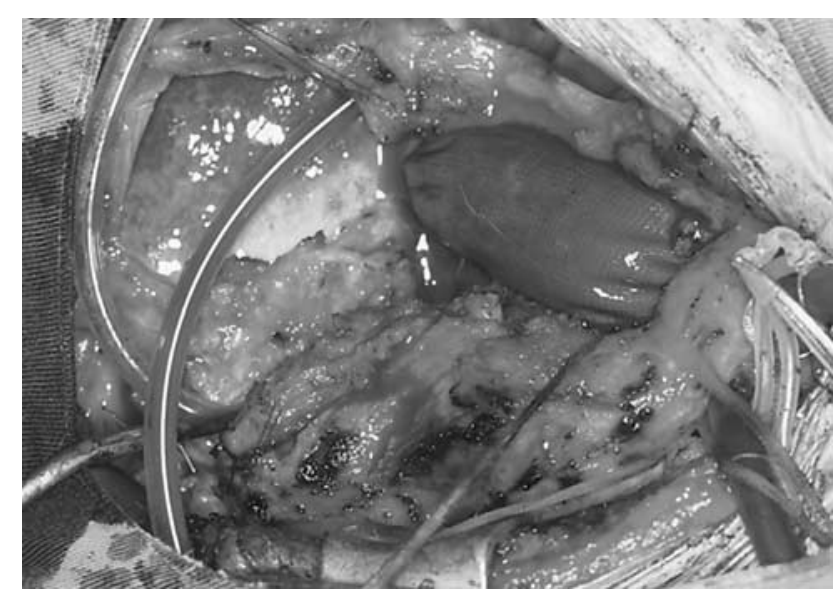

Figure 1. Intraoperative photograph. Tissue-engineered conduit 20 $\mathrm{mm}$ in diameter was anastomosed between hepatic venous stump and previous anastomotic orifice of main pulmonary artery with 4-0 Prolene suture (Ethicon, Inc, Somerville, NJ).

Pump perfusion was established with ascending aortic and single left superior vena caval cannulation. Finally, the conduit was completely removed, but hepatic veins were completely occluded and no lumen was found. Therefore the diaphragm was cut open in the midline, and the incision was extended to the hepatic veins. Tissue-engineered conduit $20 \mathrm{~mm}$ in diameter was anastomosed with 4-0 Prolene suture (Ethicon, Inc, Somerville, NJ) to the hepatic venous stump (Figure 1). The main pulmonary artery end was opened along its previous anastomotic orifice into the right pulmonary artery, and the other end of the conduit was anastomosed with the orifice. Intraoperative transesophageal echocardiography showed patent graft flow, and the patient was discharged from the hospital in good clinical condition. Postoperative computed tomography done 4 months after the operation revealed a patent graft (Figure 2).

\section{Discussion}

Significant developments have been made in the field of tissue engineering, and many clinical applications have been found in recent years. Previously we have reported the successful results of surgical implantation of tissue-engineered pulmonary valve leaflet, pulmonary artery, and inferior vena cava in large animal models..$^{2,3}$ On the basis of such reliable evidence, the first clinical application was successfully done in May 2000 with a tissue-engineered patch for pulmonary arterial angioplasty. ${ }^{4}$ The creation of tissue-engineered structures from autologous cells offers many potential advantages: elimination of the problems of rejection and donor 


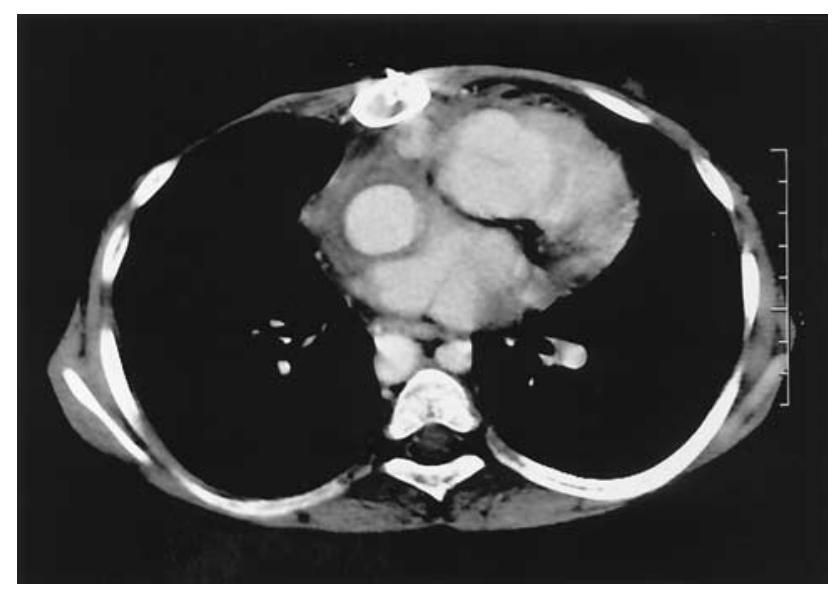

Figure 2. Postoperative computed tomographic scan. Graft is patent, and no thrombus formation is seen. Polymer scaffold has completely disappeared.

scarcity, greater durability and longevity because of the tissue's natural mechanism for repair and remodeling, lack of foreign body response or need for long-term anticoagulation, and potential for growth, which last is important in the pediatric age group. The major drawbacks and main points of criticism of the ECFO are lack of growth potential and thrombogenicity of the conduit. Hemiazygous continuation of the inferior vena cava in which conduit carries only hepatic venous flow may especially have a higher risk of thrombosis. ${ }^{5}$ In response to concerns related to the Dacron polyester fabric conduit in the venous system that we used in the initial operation, we believed that there could be less chance of obstruction because the conduit interposed between the inferior vena cava and the pulmonary artery relies on a better hydrody- namic pattern with uniform caliber and less turbulence, regardless of graft material used. ${ }^{6}$

We believe that tissue-engineered prostheses could be useful in such complicated cases, and their indications would be increased for other kinds of cases. There remain limitations of this method in the clinical setting. First, a tissue-engineered graft cannot be prepared for an emergency operation because of the prolonged in vitro times necessary for development of tissues. Second, sufficient cell proliferation cannot be accomplished in all patients, and in such cases we have to prepare cells from other part of the body. Third, tissue-engineered grafts cannot be used in systemic circulation in which proper biodegradable scaffold is now developing. Finally, small diameter vascular grafts may occlude during early follow-up. To find solutions for these issues, we are continuing experimental studies.

\section{References}

1. Haas GS, Hess H, Black M, Onnasch J, Mohr FW, van Son JA. Extracardiac conduit Fontan procedure: early and intermediate results. Eur J Cardiothorac Surg. 2000;17:648-54.

2. Shin'oka T, Shum-Tim D, Ma PX, Tanel RE, Isogai N, Langer R, et al. Creation of viable pulmonary artery autografts through tissue engineering. J Thorac Cardiovasc Surg. 1998;115:536-45.

3. Watanabe M, Shin'oka T, Tohyama S, Hibino N, Konuma T, Matsumura G, et al. Tissue-engineered vascular autograft: inferior vena cava replacement in a dog model. Tissue Eng. 2001;7:429-39.

4. Shin'oka T, Imai Y, Ikada Y. Transplantation of a tissue-engineered pulmonary artery. $N$ Engl J Med. 2001;344:532-5.

5. Konstantinov IE, Puga FJ, Alexi-Meskishvili VV. Thrombosis of intracardiac or extracardiac conduits after modified Fontan operation in patients with azygous continuation of the inferior vena cava. Ann Thorac Surg. 2001;72:1641-4.

6. Amodeo A, Galletti L, Marianeschi S, Picardo S, Giannico S, Di Renzi $\mathrm{P}$, et al. Extracardiac Fontan operation for complex cardiac anomalies: seven years' experience. J Thorac Cardiovasc Surg. 1997;114:102030. 